\title{
A política de identidade do empreendedorismo: uma análise na perspectiva da sociologia figuracional e da psicologia social crítica
}

\author{
ANGelo BRigato Ésther ${ }^{1}$ \\ ${ }^{1}$ Universidade Federal de Juiz de Fora (UFJF) / Faculdade de AdMinistração e CiÊnCIAs Contábeis, JUIZ de Fora - MG, Brasil
}

\section{Resumo}

Este artigo discute a identidade articulando elementos da perspectiva crítica em psicologia social, especialmente a partir do sintagma identidade-metamorfose-emancipação desenvolvido por Antônio Ciampa, bem como o conceito de políticas de identidade. Paralelamente, as contribuições de Norbert Elias são utilizadas para a reflexão, articulando-se às concepções de Ciampa. Para tanto, toma-se o empreendedorismo como conceito estruturador fundamental da identidade, enquanto identidade pressuposta idealizada. De todo modo, não se trata de assumir uma posição contrária ao empreendedorismo ou ao fato de alguém empreender alguma atividade. Trata-se, porém, de discutir o significado predominante que tem sido atribuído ao empreendedorismo, cuja construção constitui uma política de identidade de caráter ideológico e fetichizado.

Palavras-chave: Identidade. Política de identidade. Empreendedorismo.

Entrepreneurship and identity politics: an analysis from the perspective of figuration sociology and critical social psychology

\begin{abstract}
The article discusses the concept of identity articulating elements of the critical perspective in social psychology, especially from the syntagm identity-metamorphosis-emancipation developed by Antonio Ciampa, as well as the concept of 'identity politics.' In parallel, the study reflects on the contributions of Norbert Elias connected to the conceptions of Ciampa. Entrepreneuship is understood as a fundamental structuring concept of identity, as a presupposed, idealized identity. The study does not takes a position contrary to entrepreneurship, but discusses the prevailing meanings that have been attributed to entrepreneurship, whose construction constitutes an ideological and mythicized identity politics..
\end{abstract}

Keywords: Identity. Identity politics. Entrepreneurship.

La política de identidad del espíritu emprendedor: un análisis desde la perspectiva de la sociología figuracional y de la psicología social crítica

\section{Resumen}

Este ensayo analiza la identidad articulando elementos desde una perspectiva crítica en psicología social, especialmente a partir del sintagma identidad-metamorfosis-emancipación elaborado por Antonio Ciampa, así como el concepto de políticas de identidad. Paralelamente, se utilizan los aportes de Norbert Elias para la reflexión, para la reflexión, articulándolos a las concepciones de Ciampa. Para ello, se toma el espíritu empresarial como un concepto fundamental de la estructuración de la identidad como identidad presupuesta idealizada. En cualquier caso, no se trata de asumir una posición contraria a la iniciativa empresarial o al hecho de que alguien emprenda alguna actividad. Se trata, sin embargo, de discutir el significado predominante que se ha atribuido a la iniciativa empresarial, cuya construcción constituye una política de identidad de carácter ideológico y fetichizado.

Palabras clave: Identidad. Política de identidad. Espíritu emprendedor. 


\section{INTRODUÇÃO}

O empreendedorismo é um tema que a cada dia conquista mais espaço e adeptos quanto a seu significado, embora nem sempre de forma crítica e consciente. Isto pode implicar a difusão de uma ideologia, na medida em que se coloca o empreendedorismo como uma espécie de panaceia para todos os problemas econômicos e sociais de forma acrítica, constituindo aquilo que Chauí (2007) denomina discurso competente. Ademais, na medida em que ganha contornos de uma ideologia, também contribui para o estabelecimento de uma política de identidade, ao fornecer um referencial identitário para indivíduos, organizações e instituições, por meio de um conjunto de atributos e características desejáveis, associado a um imaginário social dentro do qual o sucesso individual e coletivo é medido e aferido por parâmetros associados ao conceito.

Tal processo constitui um estereótipo, ou seja, um conjunto de crenças relativo a características individuais de personalidade, de comportamento (DESCHAMPS e MOLINER, 2009) e formas de ação, geralmente compartilhado por determinado grupo. Por vezes, estereótipos podem se tornar tanto uma referência positiva - constituindo um grupo de estabelecidos, por exemplo (ELIAS e SCOTSON, 2000), ou uma referência negativa, constituindo grupos de outsiders (ELIAS e SCOTSON, 2000; BECKER, 2008) ou estigmatizados (GOFFMAN, 2008).

O conceito de identidade, inicialmente associado a um indivíduo, tem sido aplicado a organizações e instituições, em uma transposição reificante, que "iguala" a organização a um indivíduo, como se fossem separados e independentes a priori, como assinala a crítica de Elias (1994a) a essa concepção dominante de indivíduo e sociedade (indivíduo/coletivo). Se a separação indivíduo-sociedade (I-S) é algo dominante - como explicitado adiante neste artigo -, em tal perspectiva a identidade será compreendida da mesma forma, ou seja, pressuporá uma separação entre identidade individual e identidade coletiva. É o que Norbert Elias e Antônio Ciampa buscam evitar.

A identidade é um conceito esquivo tanto quanto o senso que a pessoa tem de sua própria identidade individual, mesmo que esta diga respeito às avaliações decisivas sobre si-mesmo, realizadas pelo indivíduo ou pelos outros (STRAUSS, 1999). Assim, este artigo discute a identidade articulando elementos da perspectiva crítica em psicologia social, especialmente a partir do sintagma identidade-metamorfose-emancipação desenvolvido por Antônio Ciampa, bem como o conceito de políticas de identidade. Paralelamente, as contribuições de Norbert Elias são utilizadas para a reflexão, articulando às concepções de Ciampa. Para tanto, toma-se o empreendedorismo como conceito estruturador fundamental da identidade, enquanto identidade pressuposta idealizada, embora destaquemos, desde já, que a rigor a identidade não se resume ou se reduz a um único critério ou parâmetro definidor (SEN, 2006), mas sobre a qual podemos evidenciar uma "face", por assim dizer. No entanto, tal face tem assumido um peso e um caráter significativos, dada sua construção ideológica.

De todo modo, não se trata de assumir uma posição contrária ao empreendedorismo ou ao fato de alguém empreender alguma atividade. Trata-se, porém, de discutir o significado predominante que tem sido atribuído ao empreendedorismo, cuja construção constitui uma política de identidade com implicações para a ação humana.

\section{As perspectivas teóricas e sua aproximação}

A trajetória histórica da psicologia enquanto área de atuação é recente no país, tendo sido a profissão de psicólogo regulamentada na década de 1960. Sua orientação era fundamentalmente positivista e seu papel se restringia, de certo modo, a contribuir para a modernização do país, o que implicava a adequação dos indivíduos aos pressupostos liberais. Nesse sentido, a perspectiva teórica - e ideológica - assumia o pressuposto de que os homens são iguais e, no limite, responsáveis por seus sucessos e fracassos, negando-se a realidade brasileira em seus aspectos sociais e culturais, herdados enquanto país colonizado (LANE, 1994). Dessa forma, não havia o reconhecimento explícito das desigualdades sociais, mantendo e potencializando as relações de dominação. No campo da psicologia social, a aplicação dos conceitos e técnicas oriundos dos Estados Unidos da América (EUA) era tomada como referência fundamental e as pesquisas visavam a encontrar leis universais, o que levaria à reprodução da ideologia capitalista hegemônica (POKER, 2014). Segundo Lima, Ciampa e Almeida (2009, p. 225), a autora assume uma posição materialista, evidenciando "que não há como separar realidade e teoria, teoria e pesquisa, tal como o faz o positivismo, para o qual o lugar do teórico, do científico é sempre um lugar neutro".

De um lado, a tradição pragmática norte-americana e seu objetivo de harmonizar as relações grupais, minimizando e negando conflitos e visando a obter produtividade do grupo, de outro, a tradição fenomenológica europeia, que buscava modelos totalizantes. Porém, as críticas, de todo lado, acabaram por evidenciar os limites da perspectiva dominante, de caráter 
ideológico e reprodutor de um ideal de homem cujo comportamento deveria ser controlado, baseado em um ideal universal e no paradigma positivista (LANE, 1994).

Assim, tal posicionamento crítico levou um grupo de pesquisadores no Brasil a considerar o homem um produto histórico e social. Nos termos de Silvia Lane (1994, p. 12), "o homem é cultura, é história”. Nesse sentido,

[...] se a psicologia descrever o que é observado ou enfocar o indivíduo como causa e efeito de sua individualidade, ela terá uma ação conservadora, estatizante - ideológica - quaisquer que sejam as práticas decorrentes. Se o homem não for visto como produto e produtor, não só de sua história pessoal, mas da história de sua sociedade, a Psicologia estará apenas reproduzindo as condições necessárias para impedir a emergência das contradições e a transformação social (LANE, 1994, p. 15).

Nessa reorientação, o papel de Lane e Codo (1994) se mostra fundamental para o caminho que se seguiu, especialmente com os trabalhos de Antônio Ciampa acerca da identidade ${ }^{1}$.

Para Antônio Ciampa, a identidade é uma questão fundamentalmente política. Com o livro A estória do Severino e a história da Severina (CIAMPA, 1987) o autor inaugura uma perspectiva que rompe com o positivismo dominante no país, rompendo, portanto, com qualquer concepção essencialista ou naturalista da identidade. Ao contrário, para Ciampa (1994, p. 64), "nós somos nossas ações, nós nos fazemos pela prática". Além disso, para o autor, os indivíduos se apresentam como portadores de múltiplos papéis, estabelecendo-se uma "intrincada rede de representações que permeia todas as relações, onde cada identidade reflete outra identidade, desaparecendo qualquer possibilidade de se estabelecer um fundamento originário para cada uma delas" (CIAMPA, 1994, p. 67). A identidade assume várias formas, mas a forma "personagem" é a que mais bem a expressa empiricamente.

Portanto, o existir humano não é garantido de antemão, nem é uma mudança natural. Ao contrário, o homem não está limitado ao seu vir-a-ser em função de um fim preestabelecido, nem está liberado das condições históricas em que vive, como se seu vir-a-ser fosse absolutamente indeterminado. Ao contrário, como afirma Habermas (1983), o adulto é capaz de construir novas identidades em situações conflitivas, por exemplo. Portanto, a questão da identidade remete a um projeto político. $O$ homem não é puramente subjetividade, consciência; tampouco é apenas uma coisa, apenas uma objetividade. Essa dualidade deve ser superada pela práxis, engajando-se em

[...] projetos de coexistência humana que possibilitem um sentido de história como realização de um porvir a ser feito com outros [...] projetos que não se definam aprioristicamente por um modelo de sociedade e de homem, que todos deveriam sofrer totalitariamente (e identicamente), mas projetos que possam tender, convergir ou concorrer para a transformação real de nossas condições de existência, de modo que o verdadeiro sujeito humano venha à existência (CIAMPA, 1994, p. 73-74).

Ainda para Ciampa (1994, p. 74-75), "identidade é movimento, é desenvolvimento do concreto. Identidade é metamorfose". A pretensão do autor é uma concepção de identidade que leve à emancipação humana ou a fragmentos de emancipação. Assim, o autor utiliza o sintagma identidade-metamorfose-emancipação como recurso para demonstrar a articulação inseparável de tais dimensões.

Nesse itinerário teórico - associado ao itinerário histórico - a psicologia social rompe com o positivismo e adota os pressupostos do materialismo histórico como base do desenvolvimento de sua teoria acerca da identidade. Evidentemente, tal mudança de rumo não se dá de modo natural ou essencial; ao contrário, ele é fruto de determinada visão de mundo, segundo a qual a emancipação é a condição possível, determinado sócio-historicamente, para a evolução da sociedade humana ao longo dos séculos (e não mais da evolução da espécie que determinava as transformações dos hominídeos na pré-história da humanidade). Uma vez compreendida como metamorfose, a identidade se desenvolve em uma sequência de formas de reconhecimento, e "esse reconhecimento, quando ausente ou feito de forma desumana, se dá a saber aos indivíduos pela experiência do aprisionamento à 'mesmice', ao fetiche de um personagem que impede a concretização do sentido emancipatório da identidade" (LIMA, 2010, p. 140).

\footnotetext{
${ }^{1}$ A obra de Silvia Lane é considerada de grande relevância para o campo da Psicologia, sendo considerada por alguns uma espécie de fundadora da chamada “Escola de São Paulo" (cf. CARVALHO, 2014). O livro organizado por ela e por Wanderley Codo é um marco na área (LANE e CODO, 1994).
} 
Considerando os ditames capitalistas liberais que impõem sua ideologia e as consequentes formas de ação desejadas, a psicologia social crítica aporta contribuições da chamada teoria crítica, especialmente a partir de Jürgen Habermas.

Baseando-se em Habermas (1983), Ciampa (2006) distingue a "identidade do eu" da "identidade de papel". Por vezes, identidades de papel (atribuídas e reproduzidas coletivamente) sugerem a existência de uma identidade a priori ou uma essência identitária. Daí a expressão "identidade convencional”. Por outro lado, a identidade "pós-convencional”, na perspectiva de Habermas, é aquela que se define pelo processo e não por um conteúdo a priori. De todo modo, a identidade de papel diz respeito a uma dimensão coletiva que remete a uma discussão fundamental, apontada por Ciampa (2006): política de identidade e identidade política.

As políticas de identidade buscam normalizar ou homogeneizar uma coletividade, levando-a a fazer com que seus membros compartilhem significados que são considerados relevantes para dar sentido à atividade de cada um. Uma identidade coletiva é considerada um conjunto de significados compartilhado por muitas pessoas que interfere de modo significativo na formação pessoal de cada um². Os grupos mais conservadores serão os maiores defensores do perfil convencional. Quanto mais um grupo ou mais exercem a hegemonia em termos de políticas de identidade, esse poder irá determinar ou influenciar o modo como cada pessoa se reconhece e é reconhecida (CIAMPA, 2006).

Ao mesmo tempo, toda identidade é política - em sua dimensão individual - na medida em que os indivíduos buscam definir-se de modo particular, ainda que articulado a um papel socialmente estabelecido. Daí deriva o conceito de personagem. Cada indivíduo é ator e autor, ao construir seu personagem mais ou menos criativamente (CIAMPA, 1987). Em ouras palavras, a identidade, em sua dimensão analítica, é tomada como elemento constitutivo das formas de sociabilidade contemporâneas (CASTRO e LISBÃO, 2017).

Seria impossível para o indivíduo viver sem personagens. No entanto, a interiorização passiva de uma intensa predicação de si (ou seja, a assimilação de identidades atribuídas, inclusive por meio das políticas de identidade) acaba por reificar a identidade, quase impedindo a possibilidade do sujeito "ser-para-si", gerando o que o autor denomina identidade mito ou fetichizada (CIAMPA, 1987).

Ao mesmo tempo, para Ciampa (2006), a noção de personagem sempre contém uma dose de transgressão, que deixa de obedecer ao convencional.

Uma identidade concretiza uma política, dá corpo a uma ideologia. No seu conjunto, as identidades constituem a sociedade, ao mesmo tempo em que são constituídas, cada uma por ela. A questão da identidade, assim... é sobretudo uma questão social, uma questão política (CIAMPA, 1987, p. 127).

A rigor,

[...] o indivíduo não é apenas um receptáculo inofensivo que incorpora as predicações e as dramatiza no cotidiano, mas também propõe novas personagens, se autodetermina; ele não apenas é um cidadão, um membro da comunidade, ele também reage a essa comunidade e a transforma com suas reações (LIMA e CIAMPA, 2012, p. 21).

Como bem afirmam os autores, o indivíduo configura sua identidade pessoal no emaranhado das relações sociais, por meio de uma história e de um projeto de vida, mediatizados pela linguagem nos diversos processos e instituições.

Em resumo, pode-se afirmar, esquematicamente, os aspectos teóricos da proposição da psicologia social crítica (LIMA e CIAMPA, 2012, p. 15):

a) A constituição do sujeito se dá em e a partir de sua inserção em uma rede de interações mediadas pela linguagem;

b) A identidade humana como metamorfose é o processo permanente que se dá ao longo da socialização;

c) A individuação, que se dá por meio da socialização, depende do e está associada ao crescimento da autonomia pessoal;

\footnotetext{
Embora a expressão "políticas de identidade" tenda a ser identificada como "um modo de compreender ações coletivas e individualizadas de uma forma que não marginalize as experiências de vida das pessoas oprimidas, ou excluídas, da sociedade pelo fato de buscarem reconhecer alguma identidade cultural e social que seja diferenciada das dominantes" (GUARESCHI, 2000), adotamos neste artigo uma concepção mais abrangente, tal como a oferecida por Ciampa (2006). No caso aqui discutido, entendemos o empreendedorismo enquanto uma política de identidade que visa a homogeneizar uma coletividade de acordo com um conjunto de significados compartilhados baseado em um modelo de sociedade e de indivíduo do ponto de vista de uma classe dominante do ponto de vista econômico. Em outras palavras, não a concebemos apenas como uma política de resistência, mas também como uma política de dominação.
} 
d) A concretização de uma pretensão identitária de um indivíduo, como expressão de autonomia, pressupõe seu reconhecimento por outros indivíduos.

É assim que Ciampa, dentro da tradição da psicologia social, procura investigar como se relacionam indivíduo e sociedade, porém, assumindo uma relação dialética entre ambos. Desde o início de seus trabalhos, Ciampa assume que "compreender a identidade é compreender a relação indivíduo-sociedade, pois assim tornar-se-ia possível perceber as questões sociais, por exemplo, as desigualdades e entraves sistêmicos, bem como compreender as formas de resistências individuais e as buscas por emancipação dos sujeitos" (SOUZA e GONÇALVES, 2017, p. 7).

Nesse aspecto, ele se aproxima da perspectiva de Norbert Elias, para quem a dicotomia indivíduo/sociedade (I-S) é uma falácia e um engano, uma "aberração intelectual" (ELIAS, 2008, p. 140). Em seu modo de ver, tais instâncias podem até ser consideradas distintas, mas jamais separadas e autônomas (ELIAS, 1994a). Nesse sentido, o autor mostra que tal concepção de divisão levou, inclusive, a uma separação entre campos de estudos: uma, para estudar o indivíduo, a psicologia; outra, a sociologia, para estudar a sociedade (ELIAS, 2008).

Segundo Norbert Elias, a sociedade é uma figuração de indivíduos interdependentes, ou seja, não existe sociedade sem indivíduos. Ao separar uma instância da outra, e admitindo-se a sociedade como uma coisa independente dos indivíduos, reforça-se a ideia de que a sociedade é constituída por estruturas que nos são exteriores e que os indivíduos são rodeados pela sociedade e separados por uma barreira invisível. Devido à sua interdependência e ao modo como as ações e experiências dos indivíduos se interpenetram, forma-se uma configuração ou um tipo de ordem relativamente autônoma, ou seja, ninguém é capaz de determinar a figuração ou sua direção como uma espécie de comandante desse processo (ELIAS, 2008) 2

Embora a identidade sofra transformações independentemente de ideologias, pelo menos no sentido do envelhecimento físico, por exemplo, considera-se que não nascemos humanos, mas que nascemos humanizáveis, tal como assumido também por Elias (1994a). Desse modo, podemos verificar que há uma metamorfose fundante, que constitui o processo de humanização e que se dá sob as condições sociais vigentes da época de nascimento. Assim, o homem é, a um só tempo, seu passado (que se apresenta no presente como história de vida) e seu futuro (que, no presente, se apresente como projeto de vida). É por isso que se pode afirmar que sempre somos nosso presente, o qual depende de nosso passado e de nosso futuro. Por isso, Ciampa se pergunta (junto com Jean-Paul Sartre): “o que faço com o que fizeram de mim?"

Dessa forma, a identidade se apresenta como um processo permanente de metamorfose, cujo sentido de luta permanente por emancipação é representado pelo sintagma identidade-metamorfose-emancipação, ou seja, não se pode falar de qualquer um dos três elementos sem falar dos outros dois. Por outro lado, por vezes a identidade se apresenta como uma "não metamorfose". Na prática, o que ocorre é que o homem acaba por repor aquilo que foi posto anteriormente, nos termos do autor, constituindo a mesmice quando nossa identidade é reposta, enquanto acontece a mesmidade quando encarnamos um outro outro que também somos (CIAMPA, 1987, 2004).

A identidade como metamorfose é possível na medida em que se tome a relação dialética entre I-S, tal como faz Elias e o próprio Ciampa. A própria ideia de emancipação de Ciampa está em consonância com tal pressuposto, pois como esta poderia ser possível se não em relação a um "outro"? Em outras palavras, o que Elias quer evitar - Ciampa também - é o perigo de acreditar que exista o indivíduo a-social, como se ele fosse um agente que existe por si, e o perigo de postular a existência de um sistema ou um todo, ou seja, uma sociedade que existiria para além do ser humano singular e para além de todos os indivíduos (ELIAS, 2006) 4 . Para o autor, a realidade objetiva é a reificação de um conceito, que tende a reforçar a ideia de que a sociedade é constituída por estruturas que nos são exteriores e que os indivíduos são rodeados pela sociedade e separados por uma barreira invisível. Segundo seu ponto de vista, no processo civilizador (ELIAS, 1994b) há uma correspondência entre a estrutura social e a estrutura de personalidade (ou estruturas psicológicas) do ser individual em determinado estágio de desenvolvimento da sociedade. Esse processo pode ser caracterizado de modo geral como o processo de mudança, repressão e controle dos comportamentos, dos instintos e dos desejos. Embora as pessoas disponham de liberdade individual de movimento, há, também, uma espécie de ordem oculta e não perceptível diretamente pelos sentidos. Cada pessoa pertence a determinado lugar, tem uma função, uma propriedade ou um trabalho específico. Nem sempre é possível sair desse lugar, de sua condição.

\footnotetext{
${ }^{3} \mathrm{O}$ autor usa os termos figuração e configuração de forma intercambiável, como sinônimos. Com o tempo ele passou a preferir o termo figuração. ${ }^{4}$ Cf. Capítulo1: Conceitos fundamentais.
} 
Ainda para o autor, essa ordem oculta não se deve a uma vontade individual nem mesmo a uma simples soma de vontades, "a uma decisão comum de muitas pessoas individuais. Não foi com base na livre decisão de muitos, num contrato social, e menos ainda com base em referendos ou eleições" (ELIAS, 1994a, p. 22). Na verdade, votações e eleições só ocorrem quando as instituições permanentes de controle social atuam aliadas a uma estrutura muito específica de funções sociais. Entretanto, ao mesmo tempo, as estruturas sociais não existem fora dos indivíduos. Em outras palavras, os indivíduos vivem por meio de relações e estas assumem figurações específicas, mas que têm suas próprias estruturas sociais.

Norbert Elias admite que a identidade é aquilo que diz respeito tanto às diferenças quanto às semelhanças entre os indivíduos em uma sociedade. No primeiro caso, o autor denomina identidade-eu; no segundo, de identidade-nós. Para discuti-la, é preciso levar em conta o estágio de desenvolvimento da sociedade. Para o autor, por exemplo, a sociedade atual favorece a identidade-eu como a dimensão mais evidente, dado o valor atribuído ao individualismo na sociedade capitalista, embora, em certos momentos, tenha havido uma precedência da identidade-nós sobre a identidade-eu. Elias (1994a, p. 130) explica tal relação da seguinte maneira:

O Estado romano republicano da Antiguidade é exemplo clássico de um estágio de desenvolvimento em que o sentimento de pertencer à família, à tribo e ao Estado, ou seja, a identidade-nós de cada pessoa isolada tinha muito mais peso do que hoje na balança nós-eu. Assim, a identidade-nós mal era inseparável da imagem que as classes formadoras da língua tinham da pessoa individual. A ideia de um indivíduo sem grupo, de uma pessoa tal como seria se fosse despojada de toda referência ao nós, tal como se afiguraria se a pessoa isolada fosse tão altamente valorizada que todas as relações-nós, como família, tribo ou Estado, fossem consideradas relativamente sem importância, essa ideia ainda estava em boa medida abaixo da linha do horizonte na práxis social do mundo antigo.

Elias explica que cada pessoa, embora singular e diferente de todas as outras, tem um habitus, ou uma composição social, que ela compartilha com as outras de sua sociedade. Em nosso modo de ver, as dimensões individual e coletiva são entrelaçadas para a compreensão dessa dialética. O indivíduo em sociedade apresenta o que o autor tem chamado de "estrutura social de personalidade", ou seja, o indivíduo se encontra em determinado "estágio e padrão de autorregulação individual" - como discutido em seu livro sobre o processo civilizador ${ }^{5}$ - associado a um habitus social. Esse habitus constitui, na visão do autor,

[...] o solo de que brotam as características pessoais mediante as quais um indivíduo se difere dos outros membros de sua sociedade. Dessa maneira, alguma coisa brota da linguagem comum que o indivíduo compartilha com outros e que é, certamente, um componente do habitus social - um estilo mais ou menos individual, algo que poderia ser chamado de grafia individual inconfundível que brota da escrita social (ELIAS, 1994a, p. 150).

Em outras palavras, o indivíduo porta em si o habitus de um grupo, que ele individualiza em maior ou menor grau. Em conformidade com sua concepção, "a existência da pessoa como ser individual é indissociável de sua existência como ser social" (ELIAS, 1994a, p. 151). A identidade eu-nós é parte constituinte do habitus social de uma pessoa, o que a deixa em aberto à individualização. A identidade é a resposta à pergunta "quem sou eu?" como ser social e individual. É importante esclarecer que, nessa dialética I-S, "não há identidade-eu sem identidade-nós. Tudo o que varia é a ponderação dos termos da balança eu-nós, o padrão da relação eu-nós" (ELIAS, 1994a, p. 152).

Em nosso modo de ver, embora jamais se referindo a Elias, a perspectiva de Ciampa é totalmente compatível com aquele autor. Elias, inclusive, refere-se à emancipação por vezes a expressando por meio do conceito de autonomia. Para o autor, um ser humano singular pode ter relativa autonomia em relação a determinadas figurações, mas em relação às figurações em geral, quando muito, apenas em casos extremos (p. ex., o da loucura). As figurações podem ter autonomia relativa em relação a determinados indivíduos que as formam no aqui e agora, mas nunca em relação aos indivíduos em geral. Dito de outra maneira:

\footnotetext{
${ }^{5}$ Nos termos de Cintya Greive Veiga (2017, p. 174), Norbert Elias "problematiza os valores envolvidos na passagem dos Estados monárquicos para os Estados nacionais, quando as classes burguesas começaram a defender direitos humanos e o progresso natural da humanidade, como argumento para a eliminação da opressão absolutista". Em síntese, o processo civilizador é caracterizado pelas alterações do "comportamento das pessoas por meio do desenvolvimento da necessidade do abrandamento de pulsões, dos impulsos e, portanto, a racionalização das atitudes, bem como a capacidade de previsão e autocontrole, na mesma proporção em que a violência física era monopolizada pelo Estado, por meio da regulamentação do campo jurídico, das penas e punições, onde não mais cabia às pessoas arbitrar sobre seus próprios conflitos (VEIGA, 2009, p. 85).
} 
Um ser humano singular pode ter uma liberdade de ação que lhe permita desligar-se de determinada figuração e introduzir-se em outra, mas se e em que medida isso é possível depende, de fato, das peculiaridades da figuração em questão. As mesmas pessoas também podem formar umas com as outras diferentes figurações [...]. Inversamente, diferentes seres humanos singulares podem formar figurações similares, com certas variações (famílias, burocracias, cidades, países) (ELIAS, 2006, p. 27).

Na concepção de Elias (2008), torna-se evidente que o poder se exerce de forma relacional, deixando de ser concebido como uma espécie de substância. Para o autor, considerando que as configurações são mutáveis, existe um equilíbrio flutuante e elástico de poder - o que ele denomina "gradiente de poder" -, e esse equilíbrio flutuante é uma característica estrutural do fluxo de cada configuração. Dependendo da complexidade da configuração - um país ou uma cidade, por exemplo - por vezes se torna difícil perceber os diversos elos de interdependência. em uma sociedade, cuja configuração é mediada pelas relações de poder, os códigos de comportamento e de sentimento são garantidos pelas coações a que os sujeitos e grupos estão expostos. Elias (1997) elenca quatro tipos:

1. Coações impostas às pessoas pelas características de sua natureza natural, como os imperativos de fome ou sede, impulso sexual, bem como aquelas associadas ao envelhecimento, morte, ao ódio e ao amor, dentre outras do gênero.

2. Coações decorrentes da dependência de circunstâncias naturais não humanas, especialmente aquela imposta pela necessidade de procurar alimento ou proteção contra o clima e as intempéries, por exemplo.

3. Coações sociais, ou seja, coações impostas mutuamente pelas pessoas no decorrer da vida social, por conta da relação inevitável da interdependência. O autor as denomina "coações externas", ressaltando que se tratam de "coações por outras pessoas". Em uma dimensão ampla, inclui pagar impostos, por exemplo, mas pode envolver apenas duas pessoas.

4. Autocoação, ou seja, diz respeito ao autocontrole. A "razão" e a "consciência" são consideradas mecanismos de autocontrole. Difere da primeira forma de coação porque essa forma existe em forma de potencial para a autocoação, ou seja, esse mecanismo precisa ser ativado ou realizado pela experiência e pela aprendizagem e depende da sociedade em que a pessoa cresce, mudando ao longo do processo de desenvolvimento humano.

Elias deixa claro que, no decorrer do processo civilizador, o mecanismo de autocoação tem se tornado mais forte do que as coações externas, tornando mais uniforme e abrangente. Segundo o autor, é comum que se desenvolva o autocontrole para o estabelecido (establishment), sobretudo em relação aos seus iguais, em sociedades com proporções de poder muito desiguais. Segundo Elias (1997), aqueles que detêm o poder, aqueles que ocupam os mais altos cargos da hierarquia, ao lidar com seus inferiores na escala social, não precisam se conter e podem, portanto, "soltar-se".

O autor deixa claro que, para compreender a experiência do indivíduo (e de grupos), não basta uma narrativa histórica, é preciso construir um "modelo teórico verificável da configuração que uma pessoa [...] formava, em sua interdependência com outras figuras sociais da época" (ELIAS, 1995, p. 18-19), como também compreender o estágio de desenvolvimento da sociedade em dado momento no tempo. É preciso compreender o "modelo das estruturas sociais da época, especialmente quando levam a diferenças de poder. Só dentro da estrutura de tal modelo é que se pode discernir o que uma pessoa [...], envolvida por tal sociedade", é capaz de fazer ou não enquanto indivíduo (ELIAS, 1995, p. 19).

\section{O empreendedorismo e o empreendedor: emergência e política de identidade}

A temática do empreendedorismo e do empreendedor vem recebendo crescente atenção e espaço, em nosso modo de ver sobretudo a partir do momento em que o país promoveu a abertura da economia no início da década de 1990 , o que implicou o fim das reservas de mercado e a adoção do livre mercado e da concorrência como vetores e paradigma do modo de desenvolvimento capitalista. Tal quadro foi reforçado, no âmbito do Estado, em sua estrutura e gestão, a partir da reforma do Estado promovida pelo governo de Fernando Henrique Cardoso, dentro dos preceitos do que, genericamente, denominamos Nova Gestão Pública (NGP), com a consequente privatização de serviços e organizações públicas e a paulatina implantação dos métodos gerenciais privados no âmbito da gestão pública. O setor público, portanto, passou a ser visto e concebido como disfuncional e incompetente, dada sua racionalidade burocrática, a qual deveria ser substituída, forçosamente, pela racionalidade empresarial, o que ficou conhecido como gerencialismo ${ }^{6}$. Onde não ocorreu a privatização, a implementação

\footnotetext{
${ }^{6}$ A Nova Gestão Pública (NGP) ou New Public Management (NPM) é embasada teoricamente no pensamento neoliberal e na teoria da escolha pública. Sua implementação decorreu, entre outros elementos, da crise do Welfare State e da ascensão do gerencialismo, sendo necessário reestabelecer a cultura
} 
da lógica empresarial foi sendo implantada paulatinamente em todos os setores, incluindo a universidade pública (ÉSTHER, 2017), e dentro do "espírito" da chamada universidade empreendedora (ÉSTHER, 2016).

Com a retirada de políticas e mecanismos de proteção de mercado governamentais, de modo geral, as empresas passaram a enfrentar a concorrência estrangeira, obrigando-as a adotar novos métodos de produção e de gestão, consubstanciados e favorecidos pela chamada reestruturação produtiva. Desde então, organizações privadas e públicas vêm adotando políticas e práticas de racionalização, o que inclui, dentre outras, a reestruturação hierárquica e a redução de quadros. Nesse contexto, o uso intensivo da tecnologia de produção, associada às tecnologias de gestão, proporcionou a redução significativa de pessoas, mas implicou uma nova postura de empregados e de gestores. Ao mesmo tempo, as reestruturações levaram a demissões de grandes contingentes, os quais, quase que da noite para o dia, tiveram de encontrar formas de sobrevivência alternativas ao emprego formal. Junte-se a isso a dificuldade dos jovens conseguirem o primeiro emprego; é nesse contexto que emerge e ganha força o discurso do empreendedorismo e a figura do empreendedor.

No âmbito da reforma do Estado, este era acusado de ter criado uma estrutura inflacionada e falida de previdência social, de possuir quadros de pessoas igualmente inflados e incompetentes, além de apresentar um padrão tecnológico defasado, aliado à ideia de que muitas funções e atividades não lhe competiam, daí as privatizações. Nesse contexto, como o desemprego era a consequência evidente, buscar emprego não constituía uma alternativa muito viável para uma massa de indivíduos. Ao mesmo tempo, de certo modo "acostumadas" à baixa concorrência e ao protecionismo estatal em vários campos, as empresas nacionais tiveram grande dificuldade para se manterem competitivas. No campo empresarial, as micro e pequenas empresas começam a emergir como alternativa ao desemprego. Nessa onda, diversas empresas e organizações estatais promoveram estímulos à demissão voluntária, pagando indenizações significativas e além do legalmente devido para aqueles que se dispusessem a se demitir.

No entanto, tal situação apenas reforçou as estatísticas de micro e pequenas empresas que quebravam antes de um, dois ou três anos de existência. Assim, a partir dessas constatações, diversas e variadas ações e iniciativas foram estabelecidas de modo a promover o empreendedorismo, mas para preparar e instrumentalizar aqueles que abriam seus pequenos negócios. Bancos abriram linhas de crédito, os governos criaram estímulos, surgiram diversos cursos e treinamentos em gestão empresarial, inclusive MBAs, e alcançando, ainda, a educação escolar média, com vistas a difundir a "cultura empreendedora" no Brasil". No campo da Administração, a literatura sobre empreendedorismo é abundante, chegando, em boa medida, a constituir verdadeiros manuais de autoajuda e promessas de sucesso garantido.

Com o processo racionalizador, favorecido pela flexibilização da legislação trabalhista no âmbito da reforma do Estado, ficou evidente a precarização do trabalho logo nos primeiros anos de sua implementação, comprovada estatisticamente e sentida até os dias de hoje. Esse processo levou à conformação de uma nova classe, o precariado - embora não apenas, mas uma mistura de precário e proletariado. Mesmo não sendo muito simples e preciso definir o termo, parece certo que a precariedade nesse sentido - "também implica a falta de identidade segura baseada no trabalho" (STANDING, 2014, p. 27). Essa é a mesma conclusão a que chegara Sennett (2009, p. 33), ao analisar as transformações do capitalismo e da sociedade, afirmando que

[...] o que é singular na incerteza hoje é que ela existe sem qualquer desastre histórico iminente; ao contrário, está entremeada nas práticas cotidianas de um vigoroso capitalismo. A instabilidade pretende ser normal, o empresário de Schumpeter ${ }^{8}$ aparecendo como o Homem Comum ideal. Talvez a corrosão de caracteres seja uma consequência inevitável.

Talvez, em outras palavras, a corrosão da identidade, devido à corrosão dos referenciais até então vigentes.

Atualmente, a "cultura empreendedora" vem impregnando as organizações e empresas, reforçada pelas mídias comuns e de negócios, as quais não se cansam de defender as virtudes e possibilidades do empreendedorismo como panaceia para os problemas econômicos e de emprego e trabalho. Ao que parece, a sociedade vem experienciando uma mudança significativa

empreendedora da era vitoriana, resultando em uma forma de gestão pública que toma o ideário empresarial como um referencial para todo o setor público (PAULA, 2005).

${ }^{7}$ O Senado brasileiro está discutindo a inserção do empreendedorismo como tema transversal nas escolas. Segundo o site do Senado, o Projeto de Lei n. 772, de 2015, altera a Lei n. 9.394, de 20 de dezembro de 1996, que estabelece as diretrizes e bases da educação nacional, para dispor que os currículos do Ensino Fundamental, anos finais, e do Ensino Médio incluirão o empreendedorismo como tema transversal. Inclui, ainda, a orientação para o trabalho e para o empreendedorismo como diretriz dos conteúdos curriculares da educação básica e, por fim, estabelece como finalidade do Ensino Superior o estímulo ao empreendedorismo e à inovação, visando à conexão entre os conhecimentos técnicos e científicos e o mundo do trabalho e da produção (BRASIL, 2015).

${ }^{8}$ Em geral, as traduções trazem o termo "empreendedor", como se vê adiante neste artigo. 
em sua estrutura e habitus sociais. Embora não se possa afirmar que tal processo está consolidado, parece-nos evidente que a força dessa ideia é crescente, alcançando quase todas as atividades humanas, pelo menos no plano do discurso. No plano econômico, tal habitus se refere ao que se denomina neoliberalismo, no qual o empreendedorismo é a chave para o sucesso do modelo, pois impõe a dimensão inovativa ao mesmo tempo em que atribui ao indivíduo, no plano comportamental, o papel central, cujas implicações são analisadas adiante.

Mas, afinal, o que significa empreendedorismo e por que seu discurso e sua narrativa são tão contundentes? Costuma-se atribuir a Jean Baptiste Say o uso do termo empreendedorismo, embora ele tenha sido difundido por Joseph Schumpeter, graças à popularização de sua ideia de destruição criativa, processo por meio do qual o novo substituiria o velho, renovando o capitalismo por meio da iniciativa individual e o espírito empreendedor, levando à inovação empresarial. No entanto, enquanto conceito, desenvolve-se no campo da gestão moderna, especialmente com os trabalhos de Peter Drucker, durante a década de 1980 (FILION, 1999; CAMPOS e SOEIRO, 2016). Desde então foram sendo apontadas algumas perspectivas acerca do empreendedorismo, inclusive tentativas de explicação do comportamento ou do espírito empreendedor a partir de diversas categorias, com características psicológicas e até traços de personalidade ou características inatas ao indivíduo (CUNNINGHAM e LISCHERON, 1991), forjando a imagem praticamente de um "super-homem".

Entretanto, o uso de "grandes figuras" tem sido evidenciado como "inspiração" e referência para ilustrar e demonstrar a força e o poder do empreendedor. Um dos ícones emblemáticos dessa força é, certamente, Steve Jobs, como bem apontam Campos e Soeiro (2016). Para os autores, sua imagem é construída tendo como base elementos que contribuem para a definição e identificação do mito Steve Jobs, ou seja, são ressaltadas somente aquelas características que denotam sua capacidade e o alcance do sucesso, este entendido como sucesso econômico e financeiro. Outras características ou situações, como, por exemplo, suas práticas de assédio moral e processos na Justiça jamais são evocadas e, mesmo quando aparecem, são suplantadas pelos traços "positivos" de sua imagem.

O uso ressaltado dos traços "positivos" é uma estratégia apontada por Elias, quando do seu estudo das relações entre os chamados "estabelecidos" e os "outsiders", em uma pequena cidade inglesa. Em suas próprias palavras, Elias e Scotson (2000, p. 22-23),

[...] o grupo estabelecido tende a atribuir ao conjunto do grupo outsider as características "ruins" de sua porção "pior" - de sua minoria anômica [...] a auto-imagem do grupo estabelecido tende a se modelar em seu setor exemplar mais "nômico" ou normativo - na minoria de seus "melhores" membros.

Tal argumento pode ser observado - embora não se refiram a ele nem a Elias - quando Campos e Soeiro (2016) apontam que, enquanto Steve Jobs é idolatrado e mitificado como protótipo do empreendedor, Tim Berners Lee, o criador da internet, que nunca a patenteou, quase nunca é lembrado, embora tenha propiciado uma incalculável contribuição ao desenvolvimento das tecnologias de informação e de comunicação. Por que isso ocorre tem a ver com a compreensão do discurso do empreendedorismo no "nível de sua produção ideológica, como narrativa legitimadora de uma determinada ordenação da vida social, suportada por uma simbologia e uma iconografia próprias" (CAMPOS e SOEIRO, 2016, p. 24).

A narrativa do empreendedorismo procura emprestar sentido às ações individuais e coletivas. Associada a um conjunto de práticas e instituições que reforçam tal narrativa, o empreendedorismo acaba por se tornar uma espécie de política de identidade, como explicitado anteriormente. Enquanto tal, procura servir de referência para a construção de identidades alinhadas a determinada ideologia, evidenciando padrões de comportamento e de ação que definem as pessoas. Tudo isso é processado e reproduzido nas diversas esferas e instâncias de socialização, construindo e reconstruindo o habitus em suas diversas camadas, e modificando as diversas figurações sociais. Esse processo pode ser compreendido, pelo menos em parte, como componente da sociodinâmica da estigmatização (ELIAS e SCOTSON, 2000), ou seja, aqueles que não se "enquadram" nesse habitus, tendem a ser excluídos. No entanto, o discurso do empreendedorismo se torna mais perverso na medida em que atribui ao indivíduo tanto o sucesso quanto o fracasso, dissimulando e camuflando qualquer referência ao caráter sóciohistórico e político da vida social.

Como bem apontam Campos e Soeiro (2016, p. 39),

[...] o empreendedorismo proporciona um quadro semiótico para interpretar eventos econômicos ao mesmo tempo que ajuda a construir esses eventos e os seus contextos econômicos. A necessidade deste imaginário, tanto mais forte quanto mais natural e remoto, não é nenhuma novidade se tivermos em consideração que todos os regimes econômicos dependem de dispositivos de legitimação moral 
que deem sentido às transformações em curso. Com efeito, o consentimento das pessoas a um dado sistema produz-se através da adesão a essas narrativas e à cultura que elas produzem. Num contexto de recuo da teoria crítica do capitalismo, um dos campos em que o trabalho de construção de um sentido global para as transformações em curso continuou a fazer-se foi precisamente o da gestão, transformada em narrativa oficial do novo capitalismo. Foi justamente a partir deste campo que o empreendedorismo se disseminou como ideologia.

Com as transformações operadas tanto no plano ideológico quanto material, as instituições também foram se transformando, perdendo seu caráter de provedoras de sentido e de identidade para os indivíduos. Para Ciampa (1998, p. 97),

[...] no nível da sociedade, a tarefa das instituições consiste em acumular sentidos e colocá-los a disposição dos indivíduos, tanto para ações particulares como para toda sua conduta de vida. As perturbações neste nível individual aparecem como crises de orientação, alienação e psicopatologias, em que a autonomia da pessoa é impedida, prejudicando o desenvolvimento de sua identidade pessoal, como sujeito dotado de capacidade de interação. Não se trata aqui, de simples adaptação, como lembra Habermas [...], mas da capacidade do sujeito seguir desenvolvendo-se mediante sucessivas readaptações sem perder o sentimento de sua própria continuidade temporal.

Nesse sentido, é interessante a crítica de Sennett (2006), quando compara a configuração do que ele denomina "novo capitalismo" em relação ao "velho". Se antes as burocracias eram consideradas instrumentos de dominação no sentido weberiano - a famosa metáfora da jaula de ferro -, sua derrocada traria mais liberdade para a sociedade moderna, segundo os defensores desse novo capitalismo. No entanto, em seus termos, é que "as mudanças não libertaram as pessoas" (SENNETT, 2006, p. 21). Em outras palavras, não propiciaram sua emancipação.

Se Elias está correto quando afirma que em sociedades com proporções de poder muito desiguais é comum o autocontrole para o estabelecido - ou a autocoação - a ideologia do empreendedorismo tem sido capaz de criar um imaginário social com o qual os indivíduos se identificam, reforçando o padrão comportamental tipificado do empreendedor - em que um Steve Jobs se constitui como figura emblemática mitificada, ou um protótipo para o empreendedor - o ideal da identidade enquanto metamorfose-emancipação de Ciampa parece ficar cada vez mais distante. Como salientam Campos e Soeiro (2016, p. 34), figuras como Steve Jobs ou Oprah são exibidas com características quase messiânicas, prontas e a ser seguidas pelas pessoas, representam "uma captura de sentido, que legitima e naturaliza uma imagem em dissonância com a realidade".

Além de tudo isso, o ideal empreendedor retira, praticamente, a dimensão coletiva da vida social, operando o distanciamento quase total entre indivíduo e sociedade, reforçando a imagem de entidades separadas e distintas. Ademais, retira o caráter coletivo do trabalho, esmaecendo a perspectiva do trabalhador enquanto classe em um sistema econômico e social desigual, atribuindo ao indivíduo um estatuto - totalmente artificial - de "dono" de sua força de trabalho, ou, ainda, de "dono" de seu próprio destino. Retira, também, qualquer entendimento e responsabilidade de governos e Estados por políticas púbicas, pois tudo seria resolvido por meio de iniciativas individuais. Por fim, faz desaparecer como mágica a relação capital-trabalho, pois tudo se resume ao indivíduo, em um mundo no qual existiriam apenas empresários autônomos.

Sob o ponto de vista da identidade, o indivíduo se tornaria empreendedor - sua identidade - apenas por seu próprio esforço e mérito, independentemente da relação com o "outro", tal como ilustrado na Figura 1. Nos termos de Campos e Soeiro (2016, p. 47), a promoção do chamado espírito empreendedor como um modo de ser acaba por constituir um "processo de inculcação destas transformações no mais fundo da identidade, através de uma tentativa de adequação da subjetividade aos princípios da maximização do lucro, da competição e da iniciativa individual que toma o mercado como soberano". Na prática, a narrativa do empreendedorismo tem construído, paralelamente, tanto a imagem do empreendedor como o protótipo de indivíduo idealizado, digno e merecedor de reconhecimento social, e a imagem daquele que não o é como seu oposto, ou seja, aquele que não alcança mérito ou sucesso porque não se esforça e, por isso, não recebe o devido reconhecimento. Assim, pode-se até afirmar que vem sendo construída uma espécie de relação estabelecido-outsider, tal como concebe Elias (2000, p. 35):

O estigma social que seus membros [dos estabelecidos] atribuem ao grupo dos outsiders transforma-se, em sua imaginação, num estigma material - é coisificado. Surge como uma coisa objetiva, implantada nos outsiders pela natureza ou pelos deuses. Dessa maneira, o grupo estigmatizador é eximido de qualquer responsabilidade: não fomos nós, implica essa fantasia, que estigmatizamos essas pessoas e sim as forças que criaram o mundo - elas é que colocaram um sinal nelas, para marcá-las como inferiores ou ruins. 
A defesa do empreendedorismo - entendido agora como ideologia - constitui a defesa de uma perspectiva excludente, pois, certamente, o mundo social não será constituído apenas por empreendedores - embora esse seja o discurso no plano ideológico e amplamente difundido. Como bem coloca Amartya Sen (2006, p. 30), "a adversidade da exclusão pode andar de mão dada com as dádivas da inclusão".

Em outras palavras, a identidade empreendedora se configuraria como uma identidade-inculcação-dominação ou identidademito, e não identidade-metamorfose-emancipação, perspectiva tão cara a Ciampa, e que pressuporia um indivíduo consciente, crítico, reflexivo e com capacidade de ação. Na balança eu-nós da identidade de Elias (1994a), o aspecto individual da identidade vem ganhando um peso cada vez maior, talvez próximo até de ofuscar a existência da identidade-nós. Daí sua força ideológica. Daí a concepção de identidade-mito, na medida em que o uso de um sistema simbólico (linguagem) acaba por favorecer uma imagem pronta a ser apropriada e assimilada pelos indivíduos (CAMPOS e SOEIRO, 2016). Enquanto política de identidade, fornece um protótipo - tal como Steve Jobs ou Oprah, por exemplo - e pretende que o indivíduo, empírica e materialmente, assuma uma identidade fetichizada, para usar a expressão de Ciampa (1987).

Figura 1

\section{Visão atomista do empreendedor}

\section{A única explicação para estar desesperado com a crise}

Só existe uma explicação para estar desesperado com a crise. Sim, uma única explicação. Se você está desesperado com ela é bem provável que você sofra desse mal, que está rapidamente se alastrando na população brasileira. Aliás, eu tenho minhas dúvidas se esse mal se disseminou entre os brasileiros por causa de períodos de estabilidade econômica ou se sempre sofremos desse incômodo.

Antes de esclarecer a única explicação para estar desesperado com a crise, vou falar sobre um pouco sobre ela. Não é necessário entrar em muitos detalhes sobre o assunto, porque você sabe que ela chegou faz algum tempo e está derrubando muita gente e muitos negócios. A questão fundamental nesse momento não é discutir as causas ou as circunstâncias desse período de turbulento, mas sim conhecer a sua maneira de reagir perante a crise.

Eu tenho notícias nada animadoras apontadas pelos maiores especialistas em economia do País, que anunciarei mesmo sabendo que será doloroso escutá-las. Os mais otimistas apontam que no segundo semestre de 2016 as coisas começarão a melhorar e os mais pessimistas dizem que só teremos uma mudança de cenário em 2017.

Isso quer dizer que, mesmo havendo margem de erro nas projeções tanto dos otimistas quanto dos pessimistas, em ambas as análises a crise permanecerá até pelo menos julho de 2016. Estou escrevendo esse artigo em fevereiro. Acabo de sair de uma reunião de empresários que me disseram que de dezembro de 2015 até agora a coisa está feia. E ainda temos março, abril, maio e junho pela frente (pelo menos).

Vejo empresários, profissionais demitidos, profissionais com medo de serem demitidos, vendedores, para citar alguns, reclamando da conjuntura conturbada do mercado. As pessoas que reclamam da situação econômica do Brasil são as mesmas que estão desesperadas com a crise. Se você é um desses que entrou em desespero, saiba que existe uma única explicação para isso: acomodação.

Eu não conheço a sua forma de reagir perante a crise, contudo, se você está apavorado com ela é porque ainda não se preparou para enfrentá-la. Você sabia que a crise chegaria? Que atitudes você adotou diante dessa informação? O que você fará até a crise continuar? O que você fará quando ela acabar? O nível de respostas para cada uma dessas perguntas demonstra o seu preparo para prosperar apesar da crise.

O Brasil já viveu períodos de estabilidade econômica, com a implantação do Plano Real, que trouxeram muitos lucros para os mesmos empresários, profissionais hoje demitidos, profissionais com medo de serem demitidos e vendedores que hoje reclamam. E você, se preparou para enfrentar a crise?

O melhor momento para planejar mudanças não é quando o perigo bate a sua porta. Pelo contrário, é quando as coisas estão em ordem que mudanças são necessárias. Em períodos instáveis a pressão e a ansiedade aumentam e as decisões precisam ser tomadas para ontem. Você precisa de tempo e de tranquilidade para tomar as melhores decisões sobre o seu futuro ou sobre o futuro da sua empresa. Isso você só consegue durante a estabilidade.

Assim, mesmo que antes você não soubesse da crise, seja pela pior maneira possível ou pela melhor, hoje você conhece a realidade da situação econômica do Brasil. Que atitudes você adotará diante dessa informação? Você vai continuar reclamando do governo, dos bancos, dos clientes e das empresas ou vai assumir a responsabilidade sobre os seus resultados?

Fonte: Muniz (2016). 


\section{CONSIDERAÇÕES FINAIS}

A esta altura, parece-nos claro que a reflexão aqui apresentada não é um posicionamento absoluto contra alguém empreender alguma atividade. Ao contrário, pessoas empreendem ações o tempo todo. A questão é o significado a que tal ação tem sido atribuída, e, sobretudo, por quê. A questão pode ser colocada de outro modo: a quem interessa tal significado? Se a uma classe dominante, que pretende e procura manter seu sistema de dominação, a construção ideológica do significado faz sentido enquanto uma política de identidade.

Aqui, a política de identidade é considerada em sentido amplo, ou seja, como busca de normalizar uma coletividade. É ideológica na medida em que naturaliza os significados compartilhados, retirando todo e qualquer caráter histórico, político e social, além de procurar construir e manter os aparatos de sua produção e reprodução.

O modelo de homem decorrente é expresso por meio de uma identidade-mito ou fetichizada, que assume, portanto, aquele caráter universal e natural, independente de qualquer coisa. Nesse sentido, a expectativa idealizada é que cada indivíduo assuma seu personagem enquanto ator, mas jamais como autor, a não ser se compatível com o protótipo idealizado. Seria, teoricamente, a incorporação do mito pelo indivíduo, nas diversas camadas do habitus social.

Em reduzindo a identidade à identidade empreendedora, por assim dizer - posto que a difusão do empreendedorismo enquanto ideologia a pressupõe como um "modo de ser", como identidade pessoal pressuposta e inequívoca-, parece ocorrer o mesmo processo de Severina no estudo de Ciampa (1987): De escrava de alguém a escrava de si-própria. 


\section{REFERÊNCIAS}

BECKER, H. Outsiders. Rio de Janeiro: Zahar, 2008.

BRASIL. Diário do Senado Federal, ano LXX, n. 199, 9 de dezembro de 2015. Disponível em: <http://legis.senado.leg.br/diarios/Busca Diario?tipDiario=1\&datDiario=09/12/2015\&paginaDireta=00043 >. Acesso em: 22 jul. 2016

CAMPOS, A.; SOEIRO, J. A falácia do empreendedorismo. Lisboa: Bertrand, 2016.

CARVAlHo, B. P. A Escola de São Paulo de Psicologia Social: uma análise do seu desenvolvimento desde o materialismo histórico. 273 f. 2014. Dissertação (Mestrado em Psicologia Social) - Programa de Mestrado em Psicologia Social, Pontificia Universidade Católica de São Paulo, São Paulo, 2014.

CASTRO, E. M. A.; LISBÃO, Y. M. Forma-personagem e fetichismo: uma leitura complementar à obra de Ciampa. Psicologia \& Sociedade, v. 29, e170759, 2017.

CHAUI, M. Cultura e democracia. São Paulo: Cortez, 2007.

CIAMPA, A. C. A estória do Severino e a história da Severina. São Paulo: Brasiliense, 1987.

CIAMPA, A. C. Identidade humana como metamorfose: a questão da família e do trabalho e a crise de sentido no mundo moderno. Interações, v. 3, n. 6, p. 87-101, 1998.

CIAMPA, A. C. Identidade. In: LANE, S. T. M.; CODO, W. (Org.). Psicologia social: o homem em movimento. São Paulo: Brasiliense, 1994. p. 58-75.

CIAMPA, A. C. Entrevista. Constr. Psicopedag., São Paulo, v. 14, n. 11, dez. 2006. Disponível em <http://pepsic.bvsalud.org/scielo. php?script=sci_arttext\&pid=S1415-69542006000100002\&Ing=es\& nrm=iso>. Acesso em: 09 nov. 2016.

CUNNINGHAM, J. B.; LISCHERON, J. Defining Entrepreneurship. Journal of Small Business Management, v. 29, n.1, p. 45-61, jan. 1991.

DESCHAMPS, J.-C.; MOLINER, P. A identidade em psicologia social. Petrópolis: Vozes, 2009.

ELIAS, N. A sociedade dos indivíduos. Rio de Janeiro: Jorge Zahar, 1994a.

ELIAS, N. O processo civilizador. Uma história dos costumes. Rio de Janeiro: Jorge Zahar, 1994b. v. 1.

ELIAS, N. Mozart: a sociologia de um gênio. Rio de Janeiro: Zahar, 1995.

ELIAS, N. Os alemães: a luta pelo poder e a evolução do habitus nos séculos XIX e XX. Rio de Janeiro: Zahar, 1997.

ELIAS, N. Escritos e ensaios. Estado, processo, opinião pública. Rio de Janeiro: Zahar, 2006. v. 1.

ELIAS, N. Introdução à sociologia. Lisboa: Ed. 70, 2008.

ELIAS, N.; SCOTSON, J. L. Os estabelecidos e os outsiders. Sociologia das relações de poder a partir de uma pequena comunidade. Rio de Janeiro: Jorge Zahar, 2000.

ÉSTHER, A. B. Qual universidade para qual sociedade? Holos, v. 32, n. 7, p. 351-365, 2016.
ÉSTHER, A. B. A universidade como universidade corporativa global? O caso da formação em Administração. GIGAPP: Estudios/Working Papers, n. 64. p. 162-178, 2017.

FILION, L. J. Empreendedorismo: empreendedorismo e proprietáriosgerentes de pequenas empresas. Revista de Administração, v. 34, n. 2, p. 5-28, 1999.

GOFFMANN, E. Estigma. Rio de Janeiro: LTC, 2008.

GUARESCHI, N. M. F. Políticas de identidade: novos enfoques e novos desafios para a psicologia social. Psicologia \& Sociedade, v. 12, n. 1-2, p. 110-124, 2000.

HABERMAS, J. Para a reconstrução do materialismo histórico. São Paulo: Brasiliense, 1983.

LANE, S. T. M. A psicologia social e uma nova concepção do homem para a psicologia. In: LANE, S. T. M.; CODO, W. (Org.). Psicologia social: o homem em movimento. São Paulo: Brasiliense, 1994. p. 10-19.

LANE, S. T. M.; CODO, W. (Org.). Psicologia social: o homem em movimento. São Paulo: Brasiliense, 1994.

LIMA, A. F. Metamorfose, anamorfose e reconhecimento perverso. São Paulo: Educ, 2010.

LIMA, A. F.; CIAMPA, A. C. Metamorfose humana em busca de emancipação: a identidade na perspectiva da psicologia social crítica. In: LIMA, A. F. (Org.). Psicologia social crítica: paralaxes do conhecimento. Porto Alegre: Sulina, 2012.

LIMA, A. F.; CIAMPA, A. C.; ALMEIDA, J. A. M. Psicologia social como psicologia política? A proposta de psicologia social crítica de Sílvia Lane. Psicologia Política, v. 9, n. 18, p. 223-236, 2009.

MUNIZ, M. A única explicação para estar desesperado com a crise. Administradores.com, João Pessoa, 24 fev. 2016. Disponível em: $<$ https://administradores.com.br/artigos/a-unica-explicacao-paraestar-desesperado-com-a-crise>. Acesso em: 02 jun. 2017.

PAULA, A. P. P. Por uma nova gestão pública. Rio de Janeiro: Ed. FGV, 2005.

POKER, T. C. D. O que eu fiz com o que as instituições fizeram de mim? A história de Molly, e a sua luta por emancipação frente às políticas de identidade no acolhimento institucional. 237 f. 2014. Dissertação (Mestrado em Psicologia Social) - Programa de Mestrado em Psicologia Social, Pontificia Universidade Católica de São Paulo, São Paulo, 2014.

SEN, A. Identidade e violência. Lisboa: Tinta de China, 2006.

SENNETT, R. A cultura do novo capitalismo. Rio de Janeiro: Record, 2006.

SENNETT, R. A corrosão do caráter. 14. ed. Rio de Janeiro: Record, 2009.

SOUZA, R. F.; GONÇALVES, A. L. V. A mesmice identitária: a (im) possibilidade de emancipação na política de assistência social. Psicologia \& Sociedade, v. 29, e171276, 2017.

STANDING, G. O precariado: a nova classe perigosa. Belo Horizonte: Autêntica, 2014.

STRAUSS, A. Espelhos e máscaras. São Paulo: Ed. USP 1999. 
VEIGA, C. G. Civilizar: tensões entre violência e pacificação nas relações de alunos e professores na institucionalização da escola pública elementar, Brasil, século XIX. In: GOETTERT, J. D.; SARAT, M. (Org.). Tempos e espaços civilizadores: diálogos com Norbert Elias. Dourados, MS: Ed. UFGD, 2009. p. 83-101.
VEIGA, C. G. Organização da nação e monopolização do ensino pelo estado: homogeneidade cultural e exclusão sociorracial (Brasil, séculos XIX e XX). Comunicações, v. 24, n. 3, p. 171-189, 2017.

Angelo Brigato Ésther

ORCID: https://orcid.org/0000-0001-9084-3746

Doutor em Administração pelo Centro de Pós-Graduação e Pesquisas em Administração (CEPEAD) na Universidade Federal de Minas Gerais (UFMG); Pós-Doutor pelo Centro de Estudos Interdisciplinares do Século XX da Universidade de Coimbra (CEIS20/UC); Líder do Socius Grupo de Pesquisa sobre a Instituição Universitária; Professor Associado da Universidade Federal de Juiz de Fora (UFJF); Professor e Coordenador do Mestrado Acadêmico em Administração na Faculdade de Administração e Ciências Contábeis. E-mail: angelo.esther@ufjf.edu.br 